\title{
Bullous pemphigoid and dipeptidyl peptidase-4 inhibitors: the importance of the pharmacotherapeutic history
}

\author{
Miguel Fernando García-Gil (1) , ${ }^{1}$ Victoria Lezcano Biosca, ${ }^{1}$ Mar García García, ${ }^{2}$ \\ Juan Monte Serrano, ${ }^{1}$ Beatriz Aldea Manrique ${ }^{1}$
}

'Department of Dermatology and Venerology, Lozano Blesa University Clinical Hospital Zaragoza, Spain ${ }^{2}$ Department of Anatomic Pathology, Lozano Blesa University Clinical Hospital, Zaragoza, Spain

\section{Correspondence to} Dr Miguel Fernando García-Gil, Department of Dermatology and Venerology, Lozano Blesa University Clinical Hospital, 50009 Zaragoza, Spain; miguelgarciagil@outlook.com

Received 4 January 2020 Revised 3 March 2020 Accepted 6 March 2020
Check for updates

(c) Author(s) (or their employer(s)) 2020. No commercial re-use. See rights and permissions. Published by BMJ.

To cite: García-Gil MF, Lezcano Biosca V, García García M, et al. Postgrad Med J Epub ahead of print: [please include Day Month Year]. doi:10.1136/ postgradmedj-2020-137491
A 97-year-old man with a history of type II diabetes mellitus was treated with oral antidiabetic agents. He went to the emergency department after the appearance of blister-like itchy lesions on the abdomen and extremities since 2 months.

The examination revealed eczematous lesions on the back, abdomen and extremities along with tense blisters on an erythematous base and serous content (figure 1A).

In the blood test carried out, $285 \mathrm{mg} / \mathrm{dL}$ glucose and $7.1 \%$ eosinophilia stood out, with no associated leucocytosis or other relevant findings. Positive glycosuria $(+++)$ was observed in urinalysis without other alterations.

A skin biopsy was performed for histological and immunofluorescence studies that confirmed the diagnosis of bullous pemphigoid (figure 1B-D).

Given the poor control of autoimmune blistering disease, possible triggers were looked for and linagliptin intake could be associated with the appearance of skin lesions 1 month earlier.

Linagliptin was replaced by metformin and the oral corticoid regimen was continued, along with high-power topical corticosteroids (clobetasol propionate), allowing a good therapeutic response.

The increase in the prevalence of type II diabetes mellitus in the population and the expanded use of

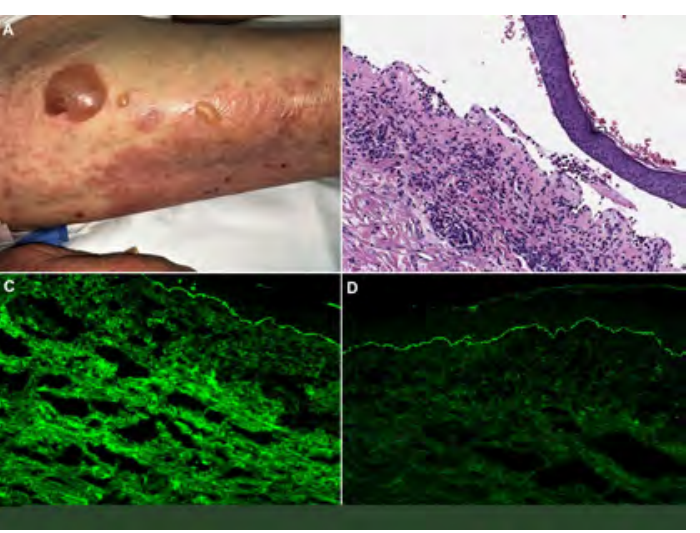

Figure 1 (A) Tense blisters as well as eczematous lesions on the thigh. (B) Subepidermal blister with inflammatory contents and eosinophils. There is a perivascular and interstitial inflammatory component of lymphocytes and eosinophils in the superficial dermis (HEx10). (C) The direct immunofluorescence study shows linear immunoglobulin $\mathrm{G}$ deposits in the epidermal basement membrane. (D) C3 deposits are also seen. oral antidiabetic agents, such as dipeptidyl peptidase-4 inhibitors (DPP4is), has led to the appearance of adverse effects which were unknown for some time.

Among these adverse effects is the occurrence of bullous pemphigoid, with an increased incidence in recent years. ${ }^{1}$ This pathology is caused by antibodies directed against proteins of the hemidesmosomes of basal keratinocytes of the epidermis. Anti-BP180 autoantibodies are known to play an important role in the pathogenesis of this autoimmune disease; however, little is known about the causes of the lack of immune tolerance to BP180 antigen in certain individuals after taking DPP4is. ${ }^{1}$

However, one proven fact is the increased incidence of bullous pemphigoid in relation to DPP4is treatment in patients with diabetes, with incidence rates of 21.1 cases (95\% CI 17.9 to 24.8 ) per 100000 person years. ${ }^{2}$ The first reported case of bullous pemphigoid induced by DPP4is dates back to $2011,{ }^{3}$ and the scientific evidence regarding the induction of bullous pemphigoid by this family of oral antidiabetic agents has been increasing since the first French and European pharmacovigilance studies that show an excessively high incidence of bullous pemphigoid. ${ }^{4}$ Since then, an overall increase in bullous pemphigoid risk has been noted in patients treated with gliptins in several studies. ${ }^{1}$

Risk estimation studies associated with treatment with gliptins have recently been carried out, finding a significant increase in the risk of developing bullous pemphigoid (OR 1.58, 95\% CI 1.25 to 2.00). The DPP4is with the greatest risk of developing bullous pemphigoid is vildagliptin (OR $1.8,95 \%$ CI 1.31 to 2.50$)$, followed by sitagliptin (OR 1.70, 95\% CI 1.19 to 2.43) and linagliptin (OR 1.64, 95\% CI 1.15 to 2.33). The increased risk is greater in males (OR 1.91, 95\% CI 1.39 to 2.63 ) than in females (OR 1.24, 95\% CI 0.88 to 1.75$).^{5}$ DPP4is-associated bullous pemphigoid also has a higher mucosal involvement $(22.2 \%$ of patients) compared with cases not associated with these antidiabetics $\left(6.5 \%\right.$ of patients). ${ }^{6}$ DPP4is may be replaced by other oral antidiabetics, such as metformin, sulfonylureas, thiazolidinediones or meglitinides, as they have not been shown to be inducers of bullous pemphigoid. ${ }^{7}$

The studies published in the literature show 20-month latency times on average (HR 3.60, 95\% CI 2.11 to 6.16 ) after the start of DPP4is usage. ${ }^{2}$ These long times between the introduction of the 


\section{Adverse drug reactions}

drug and the appearance of the skin manifestations make it difficult to identify the drug as a causal agent. However, its withdrawal induces rapid remission of the disease within as little as 10 days (Q1-Q3: 5-15 days) on average. ${ }^{4}$

Funding The authors have not declared a specific grant for this research from any funding agency in the public, commercial or not-for-profit sectors.

Competing interests None declared.

Patient consent for publication Obtained.

Provenance and peer review Not commissioned; externally peer reviewed.

ORCID iD

Miguel Fernando García-Gil http://orcid.org/0000-0002-2807-2730

\section{REFERENCES}

1 Tasanen K, Varpuluoma O, Nishie W. Dipeptidyl peptidase-4 inhibitor-associated bullous pemphigoid. Front Immunol 2019;10:1238.
2 Douros A, Rouette J, Yin H, et al. Dipeptidyl peptidase 4 inhibitors and the risk of bullous pemphigoid among patients with type 2 diabetes. Diabetes Care 2019;42:1496-503.

3 Skandalis K, Spirova M, Gaitanis G, et al. Drug-Induced bullous pemphigoid in diabetes mellitus patients receiving dipeptidyl peptidase-IV inhibitors plus metformin. J Eur Acad Dermatol Venereol 2012;26:249-53.

4 Béné J, Moulis G, Bennani I, et al. Bullous pemphigoid and dipeptidyl peptidase IV inhibitors: a case-noncase study in the French pharmacovigilance database. $\mathrm{Br} J$ Dermatol 2016;175:296-301.

5 Lee SG, Lee HJ, Yoon MS, et al. Association of dipeptidyl peptidase 4 inhibitor use with risk of bullous pemphigoid in patients with diabetes. JAMA Dermatol 2019;155:172-7.

6 Kridin K, Bergman R. Association of bullous pemphigoid with dipeptidyl-peptidase 4 inhibitors in patients with diabetes: estimating the risk of the new agents and characterizing the patients. JAMA Dermatol 2018;154:1152-8.

7 Varpuluoma O, Försti A-K, Jokelainen J, et al. Oral diabetes medications other than dipeptidyl peptidase 4 inhibitors are not associated with bullous pemphigoid: a Finnish nationwide case-control study. J Am Acad Dermatol 2018;79:1034-8. 